\title{
Modified gypsum binder for interior systems
}

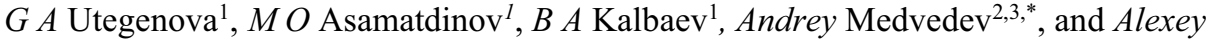 \\ Zhukov ${ }^{2,4}$ \\ ${ }^{1}$ Karakalpak State University named after Berdakh, 230100, Academician Ch. Abdirov 1, Nukus, \\ Karakalpakstan, Uzbekistan \\ ${ }^{2}$ Moscow State University of Civil Engineering, 129337, Yaroslavskoye av. 26, Moscow, Russia \\ ${ }^{3}$ Russian State Geological Prospecting University, 117997, Miklukcho-Maklaya, 23, Moscow, Russia \\ ${ }^{4}$ Research Institute of Building Physics of the Russian Academy of Architecture and Building, \\ 127238, Lokomotivny pr. 21, Moscow, Russia
}

\begin{abstract}
As the main component for many interior plaster mixes, a natural gypsum binder or its analogues is used, which are products of processing of local raw materials or by-products of other industries. Under operating conditions, gypsum binder-based plaster coatings have two main features. The first is the ability to regulate room humidity and absorb harmful emissions. The second is the ability to implement the function of barrier protection in the event of a fire. Improving the quality of plastering works and optimizing their cost is associated with the development of modified compositions based on gypsum, justified use of waste and local building materials, which include clay-gypsum binder. Clay gypsum as a natural material of sedimentary origin is widespread both in Russia and in the states formed in the post-Soviet space. In terms of energy intensity and manufacturability, the processing of raw materials into a clay-gypsum binder does not differ from the conditions of traditional processing of natural gypsum. Compared to lime or cement mortars, mortars based on gypsum binder have greater elasticity and plasticity. Such properties associated with the manufacturability of the application, such as workability and thixotropy, as well as the interval for maintaining the pot life of the mixture, are controlled by the introduction of modifying additives, the evaluation of the formulation of which was the purpose of the research, the results of which are presented in the article. The studies carried out have established that varying the recipe parameters make it possible to regulate both the strength and performance characteristics of mixtures based on gypsum plaster, as well as the manufacturability of their application.
\end{abstract}

\section{Introduction}

Complete systems have already become one of the traditional ways of introducing interior finishing works. Regardless of the type of cladding used, in interiors, less often lime, and more often gypsum plaster coatings are used, the main operational requirement for which is good adhesion to the base and the absence of negative effects on the internal

\footnotetext{
* Corresponding author: medvedev747@yandex.ru
} 
environment of the premises [1-3]. According to the criteria for the organization of work, the manufacturability of the application is important. Determined by such properties of plaster mixes as workability, thixotropy, the pot life of the mix [4-6].

The formed coating based on gypsum-containing plaster systems has a capillary-porous structure. Such a structure allows, due to the processes of sorption of water vapor and the accompanying condensation of moisture in the form of thin films, allows you to regulate the humidity in the room. Thus, excess moisture and, along with it, molecules of harmful substances are absorbed from the atmosphere of the room. When airing the premises, the reverse process takes place, and the absorbed moisture evaporates and is removed from the premises. Another important feature of gypsum, as well as of its derivatives and modifications, is the ability to release chemically bound moisture when heated. That is, non-combustible gypsum-containing facings and plaster coatings in the event of a fire perform the function of a fire-retardant barrier, and at temperatures exceeding $180^{\circ} \mathrm{C}$, dihydrate gypsum dehydrates, water evaporates, lowering the temperature of the fire effect and forming a protective vapor barrier [7-9].

Clay gypsum (ganch, drywall) has been used as a building material in the Central Asian region and Transcaucasia since ancient times. Interest in clay gypsum as a local binder and an analogue of gypsum manifested itself in the 50-70s of the last century, but the lack of a scientifically substantiated concept of its application made it impossible to effectively use the results obtained. Interest in this material is now returning. Its use is supported by low production costs, large re-serves, non-energy-intensive processing technology, and properties that meet regulatory requirements [10-12].

\section{Methods}

Clay-gypsum raw material belongs to the group of sedimentary rocks. This rock is a mechanical mixture of gypsum dihydrate and montmorillonite or kaolinite clays. This rock may contain finely dispersed calcium carbonate, silicon oxide and water-soluble salts. The impurities change the properties of the gypsum binder, which is the rationale for the general direction of research: the development of recipes and technological methods for obtaining the gypsum binder that meets the regulatory requirements for gypsum-based binders [13$15]$.

The properties of plaster mixes and plaster coatings depend on many factors. First of all, it is the material and chemical composition of the main raw material, which becomes especially important when using gypsum-containing wastes of chemical industries (for example, phosphogypsum) or local his-containing raw materials, which may include marls, sand fractions, and clays. Also important are the type, activity and concentration of modifying additives, used to correct the technological and operational characteristics of plaster mixes [16-19].

The study of the properties and formulations of clay gypsum was carried out by the method of mathematical planning of the experiment. Optimization of the obtained results was carried out by the method of mathematical planning and processing of the experimental results. The dependence of the properties of plaster mixes depending on the recipe factors was carried out in the process of implementing a three-factor experiment.

The study of the obtained dependencies (regression equations, or response functions) was carried out using the general methodology of analytical optimization developed at NRU MSBU.

The analytical optimization method is based on the application of methods of mathematical analysis to the study of response functions as a complete or incomplete quadratic equation and a mathematical function of several variables. In particular, one of 
the criteria for the extremum of a function of several variables is used for optimization: the equality of their first partial derivatives to zero.

\section{Experiments and results}

The purpose of the experiments, the results of which are presented in the article, was the development of a method for selecting the composition of a modified gypsum binder based on a comprehensive assessment of the effect of additives on the properties of this binder.

The study of scientific literature and analysis of the results of a preliminary series of experiments made it possible to identify a group of factors that influence the result to the greatest extent and to establish the intervals of their variation. Experimental conditions, factors, their average established values and variation intervals are shown in Table 1.

Taking into account the requirements of the technology for applying plaster mixtures, the following response functions are determined as the time of the plasticizer consumption $\left(\mathrm{X}_{1}\right)$ and the time of the portland cement consumption $\left(\mathrm{X}_{2}\right)$ of the gypsum binder. Using these parameters, the pot life interval of the modified clay-gypsum binder is determined, that is, the time interval of its defect-free application to the plastered surfaces. The compressive strength of the citric acid consumption $\left(\mathrm{X}_{3}\right)$ is an optimization characteristic of its properties. The gypsum binder hardens quickly, and the measurement age of 7 days is set based on regulatory requirements

Table 1. Experimental conditions.

\begin{tabular}{|l|c|c|c|c|c|}
\hline \multicolumn{1}{|c|}{ Factor name } & $\begin{array}{c}\text { Math } \\
\text { symbol, } \\
\end{array}$ & $\begin{array}{c}\text { Average } \\
\text { factor } \\
\text { value, } \bar{X}_{i}\end{array}$ & \begin{tabular}{c} 
Variatio \\
n \\
interval, \\
\cline { 4 - 6 }
\end{tabular} & & \multicolumn{2}{|c|}{ Meaning at levels } \\
\cline { 4 - 6 } & $\mathrm{X}_{1}$ & 1.0 & 0.4 & 0.6 & +1 \\
\hline $\begin{array}{l}\text { Plasticizer } \\
\text { consumption,\% }\end{array}$ & $\mathrm{X}_{2}$ & 4.6 & 1.2 & 3.4 & 5.8 \\
\hline $\begin{array}{l}\text { Portland cement } \\
\text { consumption,\% }\end{array}$ & $\mathrm{X}_{3}$ & 0.05 & 0.01 & 0.04 & 0.06 \\
\hline $\begin{array}{l}\text { Citric acid } \\
\text { consumption,\% }\end{array}$ & & & & & \\
\hline
\end{tabular}

According to the results of the experiment, after assessing the significance of the factors, regression equations were obtained for the beginning of setting $\left(\mathrm{Y}_{1}\right)$, the end of setting $\left(\mathrm{y}_{2}\right)$ and compressive strength $\left(\mathrm{y}_{3}\right)$ :

$$
\begin{gathered}
y_{1}=22+10 X_{1}+5 X_{2}+4 X_{3}-4 X_{1} X_{2}-2 X_{2} X_{3}-3 X_{1}^{2}-1 X_{2}^{2} \\
y_{2}=34+11 X_{1}+6 X_{2}+5 X_{3}-4 X_{1} X_{2}-3 X_{1}^{2}-2 X_{2}^{2} \\
y_{3}=8.1+2.2 X_{1}+1.6 X_{2}+1.2 X_{3}+0.8 X_{2} X_{3}-1.2 X_{2}^{2}
\end{gathered}
$$

Confidence intervals were determined for each response function separately based on the convergence of parallel experiments and the value of the t-test. Accordingly, the confidence intervals are: $\Delta \mathrm{b}_{1}=0.8 ; \Delta \mathrm{b}_{2}=1.0 ; \Delta \mathrm{b}_{3}=0.4$. The coefficients of the regression equations that are less in absolute value than the certain confidence intervals were considered insignificant and equated to zero. 


\section{Discussion}

The analysis of the equations shows that, on the areas for determining the variable factors established according to the experimental conditions (Table 1), the plasticizer consumption and, to a lesser extent, the consumption of Portland cement (coefficients at $\mathrm{X}_{1}$ and $\mathrm{X}_{2}$ ) have the greatest influence on the setting time.

With an increase in the consumption of the plasticizer, the timing of both the beginning and the end of setting increases significantly (coefficients at $\mathrm{X}_{1}{ }^{2}$ ), and the increase in the effect of the consumption of Portland cement on increasing the beginning of setting gradually slows down (negative coefficients at $\mathrm{X}_{2}{ }^{2}$ ). The presence of antagonistic effects of the combined effect of the plasticizer consumption and the consumption of Portland cement, as well as the consumption of Portland cement and citric acid on the setting time (negative coefficients at $\mathrm{X}_{1} \mathrm{X}_{2}$ and $\mathrm{X}_{2} \mathrm{X}_{3}$ ) is due to the nature of the chemical interaction of these components.

The greatest influence on the compressive strength is exerted by the consumption of the plasticizer (coefficient at $\mathrm{X}_{1}$ ), and the influence of the consumption of Portland cement and citric acid is manifested to a lesser extent. But it is also very significant (coefficients at $\mathrm{X}_{2}$ and $\mathrm{X}_{3}$ ). There is also a synergistic effect of the combined effect of the consumption of Portland cement and citric acid on the strength of the plaster coating (positive coefficient at $\mathrm{X}_{2} \mathrm{X}_{3}$ ), due to the nature of the interaction of free calcium hydroxide and polar radicals during the formation of the structure of the material.

The significant value of the coefficient at $\mathrm{X}_{2}^{2}$ allows the use of an analytical method to optimize this dependence, that is, functions of three variables $\mathrm{Y}_{3}=f\left(\mathrm{X}_{1}, \mathrm{X}_{2}, \mathrm{X}_{3}\right)$.

1). Based on the general methodology of analytical optimization, we study the function $\mathrm{y}_{3}=f\left(\mathrm{X}_{1}, \mathrm{X}_{2}, \mathrm{X}_{3}\right)$ by methods of mathematical analysis: we determine its optimum in the partial derivative with respect to the variable $\mathrm{X}_{2}$ :

$$
\begin{aligned}
& \partial y_{3} / \partial X_{2}=1,6-0,8 X_{3}-2,4 X_{2}=0 \\
& X_{2}=0,67-0,33 X_{3}
\end{aligned}
$$

An analytical study of the strength function $\mathrm{y}_{3}=f\left(\mathrm{X}_{1}, \mathrm{X}_{2}, \mathrm{X}_{3}\right)$ showed that the optimal consumption of Portland cement $\left(\mathrm{X}_{2}\right)$ is a function of the consumption of citric acid $\left(\mathrm{X}_{3}\right)$ introduced into the mortar to regulate the setting time. The transition from coded values of the factor to natural (using the data in Table 1) allows us to conclude that the optimal consumption of Portland cement is from 4.8 to $5.8 \%$

2). We solve the mathematical polynomials $\mathrm{y}_{1}$ and $\mathrm{y}_{2}$ by substituting the optimization function and taking into account the confidence intervals $\Delta \mathrm{b}_{1}=0.8 ; \Delta \mathrm{b}_{2}=1.0$. As a result, we get the dependences optimized for $\mathrm{X}_{2}$ :

$$
\begin{gathered}
y_{1}=25+10 X_{1}+1,7 X_{3} \\
y_{2}=37+8 X_{1}+4 X_{3}+1,2 X_{1} X_{3}-3 X_{1}^{2} \\
y_{3}=8,6+2,2 X_{1}+0,6 X_{3}
\end{gathered}
$$

The graphic interpretation of the obtained dependencies made it possible to construct nomograms (Fig. 1), with the help of which it is possible to determine the optimal values of the consumption of plasticizer, Portland cement and citric acid and to estimate the setting time of the modified gypsum binder (sectors I and II of the nomogram) and the values strength of the hardened plaster coating (sector III of the nomogram) . 
Using the nomogram allows you to establish preliminary results, and, first of all, to estimate the costs of the main components of the modified clay-gypsum binder, set based on the requirements for the strength and pot life of the mixture. Further, control mixes are carried out and the actual values of the setting time of the clay-gypsum test and the strength of the plaster coating samples are determined. The control tests carried out showed an error in the results. Not exceeding $8 \%$.

Optimization equations (as well as basic polynomials) confirm that in the ranges of factors used in the experiment (Table 1), the consumption of superplasticizer C-3 has the greatest influence on the result.

The use of gypsum plasters, including those based on modified glingypsum binder, makes it possible to form high-quality plastered surfaces of light gray color and to minimize the filling work. The final decorative coating (decorative plaster, wallpaper, etc.) can be applied directly to the plaster layer.

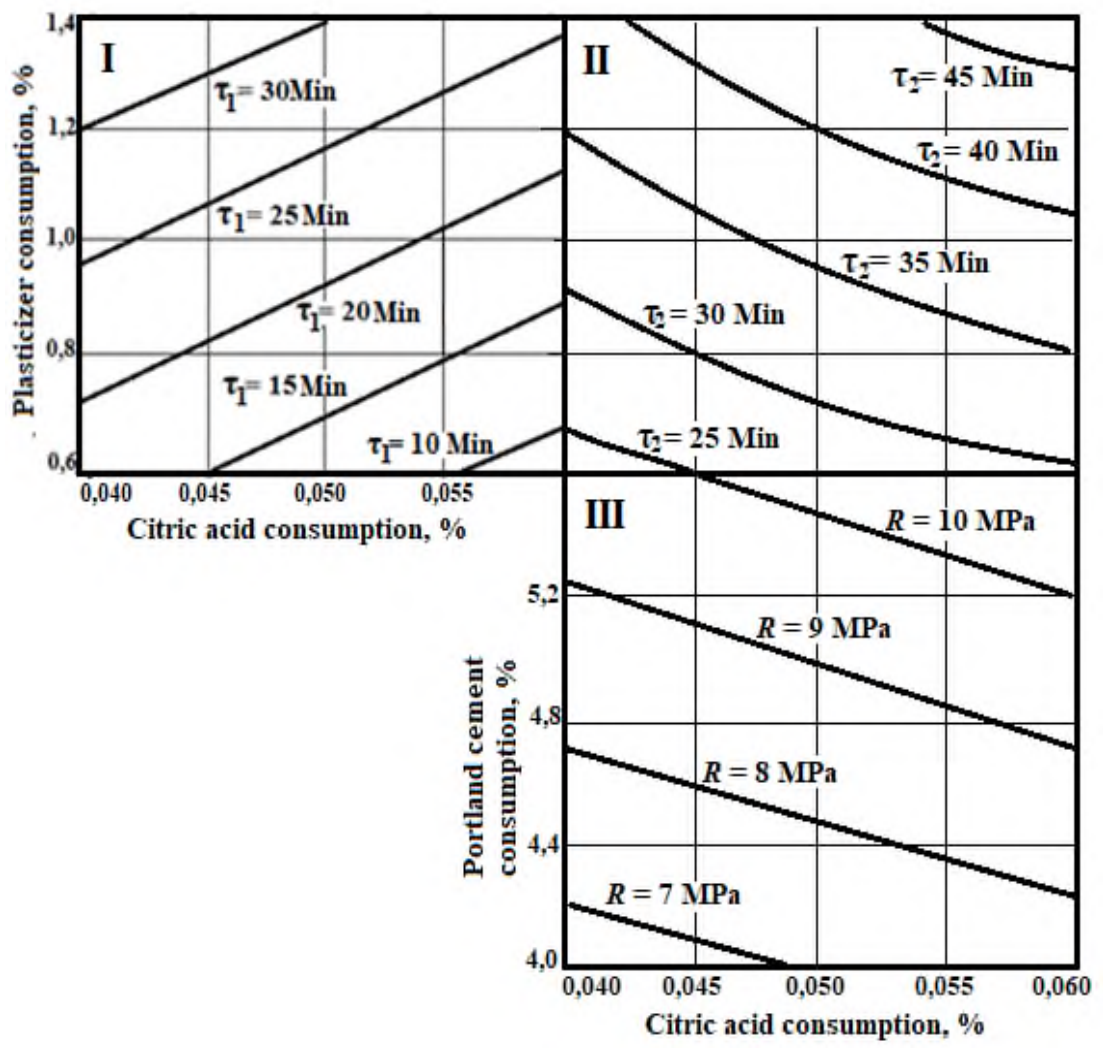

Fig. 1. Nomograms for determining the characteristics of the modified clay-gypsum binder: I - the beginning of setting $(\tau 1, \mathrm{~min}$.); II - end of setting $(\tau 2$, min.); III - compressive strength $(\mathrm{R}, \mathrm{MPa})$.

\section{Conclusions}

The solution of technological problems with the use of experimental planning, the implementation of field studies in the laboratory and the use of modern methods of processing and optimization of experimental data significantly increases the efficiency of research, and ensures obtaining reliable results that adequately correspond to real processes. 
The developed technique for selecting the composition of the modified clay-gypsum binder is based on the use of nomograms obtained as a result of the experiment, processing of mathematical polynomials, and analytical optimization of the results.

The use of a modified clay-gypsum binder and products based on it, including interior plaster mixes, makes it possible to expand the possibilities of the raw material base and reduce the labor intensity of applying plaster coating. The use of local raw material bases allows to optimize logistics, reduce transportation costs and ensure the stability of the supply of both raw materials and finished products.

\section{References}

1. M-B. Kh. Kodzoev, S. L. Isachenko, et al., MATEC Web of Conferences 170, 03022 (2018) DOI: https://doi.org/10.1051/matecconf/201817003022

2. B. M. Rumyantsev, Internet Bulletin of VolgSABU 3(23), 3 (2014)

3. M. Asamatdinov, E. Shokodko, A. Ushakov, et al., E3S Web of Conf. 97 (2019) DOI: https://doi.org/10.1051/e3sconf/20199702006

4. V. F. Korovyakov, Materials of the All-Russian seminar "Increasing the efficiency of production and use of gypsum materials and products", RAASN, Moscow, $51-56$ (2002)

5. I. V. Bessonov, Materials of the All-Russian seminar "Increasing the efficiency of production and use of gypsum materials and products", RAASN, Moscow, 82-87 (2002)

6. A. D. Zhukov, Scientific Review 7, 209-212 (2015)

7. V. I. Telichenko, D. V. Oreshkin, Ecology of Urbanized Territories 2, 31-33 (2015)

8. M. Asamatdinov, A. Zhukov A. Medvedtv, E3S Web of conferences 175, 11008 (2020) https://doi.org/10.1051/e3sconf/202017511008

9. V. S. Semenov, I. V. Bessonov, K. A. Ter-Zakaryan, et al., Regional Energy Problems (Electronic edition) 4 (2020) DOI: 10.5281/zenodo.4018999 UDC: 691.1752./6./8

10. D. E. Caetano, et al., Materials Design and Applications, 257-277 (Springer, Cham, 2017)

11. M. O. Asamatdinov, A. A. Medvedev, A.D., Zhukov, et al., Modeling of the composition of ecologically safe clay-gypsum binder, MATEC Web of Conferences DOI: https://doi.org/10.1051/matecconf/201819303045

12. E. R. Pyataev, A. A. Medvedev, A. I. Poserenin, et al., Theoretical principles of creation of cellular concrete with the use of secondary raw materials and dispersed reinforcement, IPICSE DOI: https://doi.org/10.1051/matecconf/201825101012

13. A. Zhukov, E. Shokodko, Advances in Intelligent Systems and Computing 1116, 413421 (2020) DOI: https://doi.org/10.1007/978-3-030-37919-3_40

14. A. D. Zhukov, E. Yu. Bobrova, I. V. Bessonov, et al., Nanotechnology in Construction 12(6), 313-319 (2020) DOI: 10.15828 / 2075-8545-2020-12-6-313-319

15. A. D. Zhukov, V. F. Korovyakov, M. O. Asamatdinov, A. S. Chkunin, Scientific Review 7, 86-90 (2016)

16. A. D. Zhukov, V. F. Korovyakov, M. O. Asamatdinov, Innovations in Life 1(20), 104113 (2017)

17. N. Kondratieva, M. Barre, F. Goutenoire, M. Sanytsky, et al., Construction and Building Materials 149, 535-54 (2017) 